\title{
Hypertensive disorders in pregnancy
}

\author{
Wilbert S. Aronow \\ Cardiology Division, Department of Medicine, Westchester Medical Center and New York Medical College Valhalla, NY, USA \\ Correspondence to: Wilbert S. Aronow, MD, FACC, FAHA. Cardiology Division, Westchester Medical Center and New York Medical College, Macy \\ Pavilion, Room 141, Valhalla, NY 10595, USA. Email: wsaronow@aol.com.
}

Submitted Mar 04, 2017. Accepted for publication Mar 20, 2017.

doi: 10.21037/atm.2017.03.104

View this article at: http://dx.doi.org/10.21037/atm.2017.03.104

Hypertensive disorders of pregnancy occur in approximately $10 \%$ of pregnant women and preeclampsia in approximately $3 \%$ of pregnancies in the United States (1). The American College of Obstetricians and Gynecologists Task Force on Hypertension in Pregnancy defined chronic hypertension as a systolic blood pressure of $140 \mathrm{mmHg}$ or more or a diastolic blood pressure of $90 \mathrm{mmHg}$ or more on two separate occasions at least $2 \mathrm{~h}$ apart occurring before pregnancy or developing less than 20 weeks during pregnancy (2). Mild hypertension is a systolic blood pressure of $140-149 \mathrm{mmHg}$ or a diastolic blood pressure of 90-99 $\mathrm{mmHg}$ (3). Moderate hypertension during pregnancy is a systolic blood pressure of $150-159 \mathrm{mmHg}$ or a diastolic blood pressure of 100-109 $\mathrm{mmHg}$ (3). Severe hypertension during pregnancy is a systolic blood pressure of $160 \mathrm{mmHg}$ or higher or a diastolic blood pressure of $110 \mathrm{mmHg}$ or higher (3). Gestational hypertension occurs after 20 weeks during pregnancy (2). Preeclampsia is diagnosed if the woman has hypertension after 20 weeks of pregnancy with proteinuria greater than $300 \mathrm{mg}$ in a 24-hour urine collection or a urinary protein/ creatinine ratio $\geq 0.3$ (2). Severe features of preeclampsia include thrombocytopenia, renal insufficiency, impaired liver function, pulmonary edema, and cerebral or visual symptoms (2). Modifiable risk factors for hypertensive disorders in pregnancy include increased body mass index, anemia, increased dietary sodium, and decreased dietary potassium intake $(4,5)$.

A study of 12,055 Finnish women demonstrated that gestational hypertension was associated at a mean followup of 39.4 years with a $44 \%$ increase in ischemic heart disease, a $75 \%$ increase in myocardial infarction, a 3 times increase in death from myocardial infarction, a $78 \%$ increase in heart failure, a $59 \%$ increase in ischemic stroke, and a $91 \%$ increase in kidney disease (6). A study of Danish women showed that the risk of subsequent hypertension was increased 5.31 times after gestational hypertension, 3.61 times after mild preeclampsia, and 6.07 times after severe preeclampsia (7). This study showed that the risk of subsequent type 2 diabetes mellitus was increased 3.12 times after gestational hypertension and 3.68 times after severe preeclampsia. The risk of ischemic heart disease was increased 1.48 times after gestational hypertension, 1.57 times after mild preeclampsia, and 1.61 times after severe preeclampsia (7). The risk of stroke was also increased 1.51 times after gestational hypertension, 1.43 times after mild preeclampsia, and 1.58 times after severe preeclampsia (7).

A meta-analysis of 3,488,160 women included 198,252 women with preeclampsia (8). Women with preeclampsia had a 3.70 times increased risk of hypertension after 14.1 years, a 2.16 times increased risk of ischemic heart disease after 11.7 years, and a 1.81 times increased risk of stroke after 10.4 years (8). A Scottish cohort study showed that the risk of stroke was increased 2.42 times by gestational hypertension and 3.39 times by preeclampsia/ eclampsia (9).

A Danish study showed that the risk of subsequent cardiomyopathy was increased 2.06 times by gestational hypertension, 1.89 times by moderate preeclampsia, and 2.20 times by severe preeclampsia (10). A Canadian study showed that the risk of subsequent heart failure or atrial or ventricular arrhythmias at a mean duration of 7.8 years was increased 2 times by a hypertensive disorder of pregnancy (11). Preeclampsia also increased the risk of stage B heart failure 4.3 times (12).

A meta-analysis of seven studies showed at 7.1 years postpartum that women with preeclampsia had a 4.31 times 
increased risk of microalbuminuria (13). A Taiwanese study showed that women with hypertensive disorders during pregnancy had a 9.38 times increased risk of chronic kidney disease and a 12.4 times increased risk of end-stage renal disease (14). A Scottish record linkage study showed that the subsequent risk of chronic kidney disease was increased 1.36 times by gestational hypertension and 1.93 times by preeclampsia (15).

There are three Cochrane database reviews of treatment of mild to moderate hypertension during pregnancy (16-18). One study showed that oral beta blockers reduced the risk of severe hypertension by $63 \%$ and the need for additional antihypertensive drugs by $56 \%$ (16). There were insufficient data to show the effect of beta blockers on perinatal mortality or preterm birth (16). Another study of two small trials showed insufficient evidence to determine whether reduction of the blood pressure to less than $130 / 80 \mathrm{mmHg}$ was better than reduction of the blood pressure to less than $140 / 90 \mathrm{mmHg}$ to improve maternal and fetal-neonatal outcomes (17). A third study showed that antihypertensive drug treatment reduced the risk of severe hypertension by $51 \%$ (18). Compared with methyldopa, beta blockers and calcium channel blockers reduced the risk of developing proteinuria/preeclampsia by $27 \%$ (18).

A randomized study of 987 women with non-proteinuric preexisting or gestational hypertension randomized to a diastolic blood pressure below $85 \mathrm{mmHg}$ or to less than $100 \mathrm{mmHg}$ showed that severe hypertension developed in $40.6 \%$ of women with less tight control versus $27.5 \%$ of women with tighter control (19). A prospective observational study of 222 women with mild to moderate hypertension demonstrated that cessation of antihypertensive drug therapy increased maternal and fetal morbidity (20). Forty-six studies showed that mild chronic hypertension during pregnancy increased the risk for perinatal mortality 3.4 times and increased the risk for placental abruption 2.1 times (21). This review emphasized that use of angiotensin-converting enzyme (ACE) inhibitors during the second or third trimester increases renal failure and use of atenolol early in pregnancy restricts fetal growth (21). In addition to use of ACE inhibitors or angiotensin receptor blockers (ARBs) causing fetal renal damage in pregnancy, these drugs cause lower birth weight and gestational age and increase the risk for miscarriage (22). ARBs also cause a high prevalence rate of oligohydramnios (23). Direct renin inhibitors should also not be administered (2).

The European Society of Cardiology (ESC) guidelines recommend treating mild to moderate hypertension with antihypertensive drug therapy to a level below $140 / 90 \mathrm{mmHg}$ in pregnant women with gestational hypertension, pre-existing hypertension with the superimposition of gestational hypertension, and hypertension with subclinical organ damage or symptoms at any time during pregnancy (24). Nifedipine and labetalol are considered first-line drugs for treatment of hypertensive disorders in pregnancy (1). Methyldopa may also be used (1). Hypertensive emergencies should be treated with intravenous labetalol, oral nifedipine, or intravenous hydralazine $(1,25)$ or with intravenous sodium nitroprusside (24). Sodium nitroprusside should be used only in extreme emergencies and used for the shortest amount of time possible because of cyanide and thiocyanate toxicity in the mother and fetus or newborn and increased intracranial pressure in the mother (26). The antihypertensive drugs labetalol, nifedipine, methyldopa, and hydralazine are considered safer in breastfeeding (1).

The ESC guidelines recommend induction of delivery in patients with gestational hypertension with proteinuria with adverse conditions such as fetal distress, visual disturbances, or coagulation abnormalities (24). A Cochran database review published in 2017 included five studies with 1,819 women with hypertensive disorders randomized to planned early delivery by induction of labor or by caesarean section compared with expectant management from 34 weeks gestation (27). Women randomized to receive planned early delivery had a $31 \%$ reduction in maternal mortality and severe morbidity, a $60 \%$ lower risk of the HELLP syndrome, and a $64 \%$ reduction in severe renal impairment (27). There were insufficient data to draw any conclusions about the effect of planned early delivery on infant mortality and severe morbidity.

\section{Acknowledgements}

None.

\section{Footnote}

Conflicts of Interest: The author has no conflicts of interest to declare.

\section{References}

1. Amro FH, Moussa HN, Ashimi OA, et al. Treatment options for hypertension in pregnancy and puerperium. Expert Opin Drug Saf 2016;15:1635-42. 
2. Roberts JM, August PA, Bakris G, et al. Hypertension in pregnancy. Report of the American College of Obstetricians and Gynecologists' Task Force on Hypertension in Pregnancy. Obstet Gynecol 2013;122:1122-31.

3. Visintin C, Mugglestone MA, Almerie MQ, et al. Management of hypertensive disorders during pregnancy: summary of NICE guidance. BMJ 2010;341:c2207.

4. Umesawa M, Kobashi G. Epidemiology of hypertensive disorders in pregnancy: prevalence, risk factors, predictors and prognosis. Hypertens Res 2017;40:213-20.

5. Yılmaz ZV, Akkaş E, Türkmen GG, et al. Dietary sodium and potassium intake were associated with hypertension, kidney damage and adverse perinatal outcome in pregnant women with preeclampsia. Hypertens Pregnancy 2017;36:77-83.

6. Männistö T, Mendola P, Vääräsmäki $M$, et al. Elevated blood pressure in pregnancy and subsequent chronic disease risk. Circulation 2013;127:681-90.

7. Lykke JA, Langhoff-Roos J, Sibai BM, et al. Hypertensive pregnancy disorders and subsequent cardiovascular morbidity and type 2 diabetes mellitus in the mother. Hypertension 2009;53:944-51.

8. Bellamy L, Casas JP, Hingorani AD, et al. Pre-eclampsia and risk of cardiovascular disease and cancer in later life: systematic review and meta-analysis. BMJ 2007;335:974.

9. Wilson BJ, Watson MS, Prescott GJ, et al. Hypertensive diseases of pregnancy and risk of hypertension and stroke in later life: results from cohort study. BMJ 2003;326:845.

10. Behrens I, Basit S, Lykke JA, et al. Association Between Hypertensive Disorders of Pregnancy and Later Risk of Cardiomyopathy. JAMA 2016;315:1026-33.

11. Ray JG, Schull MJ, Kingdom JC, et al. Heart failure and dysrhythmias after maternal placental syndromes: HAD MPS Study. Heart 2012;98:1136-41.

12. Ghossein-Doha C, van Neer J, Wissink B, et al. Preeclampsia: an important risk factor for asymptomatic heart failure. Ultrasound Obstet Gynecol 2017;49:143-9.

13. McDonald SD, Han Z, Walsh MW, et al. Kidney disease after preeclampsia: a systematic review and meta-analysis. Am J Kidney Dis 2010;55:1026-39.

14. Wang IK, Muo CH, Chang YC, et al. Association between hypertensive disorders during pregnancy and end-stage renal disease: a population-based study. CMAJ 2013;185:207-13.

15. Ayansina D, Black C, Hall SJ, et al. Long term effects of gestational hypertension and pre-eclampsia on kidney function: Record linkage study. Pregnancy Hypertens 2016;6:344-9.
16. Magee LA, Duley L. Oral beta-blockers for mild to moderate hypertension during pregnancy. Cochrane Database Syst Rev 2003;(3):CD002863.

17. Nabhan AF, Elsedawy MM. Tight control of mild-moderate pre-existing or non-proteinuric gestational hypertension. Cochrane Database Syst Rev 2011;(7):CD006907.

18. Abalos E, Duley L, Steyn DW. Antihypertensive drug therapy for mild to moderate hypertension during pregnancy. Cochrane Database Syst Rev 2014;(2):CD002252.

19. Magee LA, von Dadelszen P, Rey E, et al. Less-tight versus tight control of hypertension in pregnancy. $\mathrm{N}$ Engl J Med 2015;372:407-17.

20. Rezk M, Ellakwa H, Gamal A, et al. Maternal and fetal morbidity following discontinuation of antihypertensive drugs in mild to moderate chronic hypertension: A 4-year observational study. Pregnancy Hypertens 2016;6:291-4.

21. Ferrer RL, Sibai BM, Mulrow CD, et al. Management of mild chronic hypertension during pregnancy: a review. Obstet Gynecol 2000;96:849-60.

22. Moretti ME, Caprara D, Drehuta I, et al. The Fetal Safety of Angiotensin Converting Enzyme Inhibitors and Angiotensin II Receptor Blockers. Obstet Gynecol Int 2012;2012:658310.

23. Shimada C, Akaishi R, Cho K, et al. Outcomes of 83 fetuses exposed to angiotensin receptor blockers during the second or third trimesters: a literature review. Hypertens Res 2015;38:308-13.

24. Regitz-Zagrosek V, Blomstrom LC, Borghi C, et al. ESC Guidelines on the management of cardiovascular diseases during pregnancy: the Task Force on the Management of Cardiovascular Diseases during Pregnancy of the European Society of Cardiology (ESC). Eur Heart J 2011;32:3147-97.

25. ElFarra J, Bean C, Martin JN Jr, et al. Management of Hypertensive Crisis for the Obstetrician/Gynecologist. Obstet Gynecol Clin North Am 2016;43:623-37.

26. Committee on Obstetric Practice. Committee Opinion No. 623: Emergent therapy for acute-onset, severe hypertension during pregnancy and the postpartum period. Obstet Gynecol 2015;125:521-5.

27. Cluver C, Novikova N, Koopmans CM, et al. Planned early delivery versus expectant management for hypertensive disorders from 34 weeks gestation to term. Cochrane Database Syst Rev 2017;1:CD009273.

Cite this article as: Aronow WS. Hypertensive disorders in pregnancy. Ann Transl Med 2017;5(12):266. doi: 10.21037/ atm.2017.03.104 